\title{
Por que a graduação em Letras-Inglês pode ter o status de formação contínua? ${ }^{1}$
}

\section{Why may the English Language undergraduate program be considered continuing education?}

Paulo Boa Sorte*

Universidade Federal de Sergipe

Aracaju - Sergipe / Brasil

\begin{abstract}
RESUMO: Atribuir a um curso de graduação o status de formação contínua pode soar contraditório, a princípio. Entretanto, no contexto brasileiro, há particularidades marcantes a serem observadas. Antes mesmo de concluírem a faculdade, alunos de Letras têm a possibilidade de assumir aulas de inglês em institutos de idiomas e/ou escolas públicas e privadas. Discutir os motivos pelos quais a graduação em Letras-Inglês pode ter o status de formação contínua é o ponto central deste artigo, cujos fundamentos teóricos são Celani (2001, 2010), Perrenoud (2002), Cunha (2003), Menezes (2003), Azambuja (2007), Hepp (2008) e Vieira-Abrahão (2010). Além disso, são utilizadas entrevistas semiestruturadas (RIZZINI, 1999) que captam os sentidos e significados (VYGOTSKY, 1934/2010) sobre formação docente atribuídos por alunosprofessores de Letras com experiência.
\end{abstract}

PALAVRAS-CHAVE: formação contínua; graduação em Letras-Inglês; professores de inglês experientes.

ABSTRACT: Attributing the status of continuing education to an undergraduate program may sound contradictory at first. However, in the Brazilian context, there are marked peculiarities to be observed. Even before finishing college, students of English language undergraduate programs are allowed to teach English classes at language institutes and/or public and private schools. Discussing the reasons why an undergraduate program in English Language may have the status of continuing education is the focus of this article, whose theoretical basis are Celani (2001, 2010), Perrenoud (2002), Cunha (2003), Menezes (2003), Azambuja (2007), Hepp (2008) and Vieira-Abrahão (2010). Semi-structured interviews (RIZZINI, 1999) were used to capture the senses

*pauloboasorte@yahoo.com

${ }^{1}$ Este artigo é um dos resultados da minha tese de doutorado defendida no Programa de Estudos Pós-graduados em Linguística Aplicada e Estudos da Linguagem da PUC-

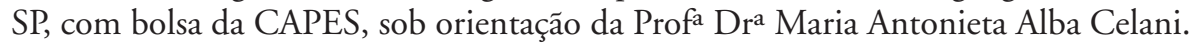


and meanings (VYGOSTKY, 1934/2010) on teacher education attributed by experienced student-teachers of the English language.

KEYWORDS: continuing education; English language undergraduate program; experienced English teachers.

\section{Introdução}

Este artigo discute as possibilidades de entender a graduação em LetrasInglês como formação contínua para alunos que já atuam como professores, isto é, que possuem experiência, seja em institutos de idiomas seja em escolas regulares públicas ou privadas. O objetivo inicial é discutir, teoricamente, as possibilidades desse entendimento, revisitando os conceitos de formação de professores de inglês, de formação inicial e formação contínua. Em seguida, para oferecer suporte a essa discussão, apresento excertos de entrevistas concedidas por alunos-professores de inglês experientes, que revelam os sentidos e significados atribuídos à formação que recebem, reforçando a necessidade de se desfazer a visão unilateral de que o curso de graduação deve ser concebido apenas como formação inicial.

\section{A graduação em Letras-Inglês como espaço de formação contínua}

Atribuir a um curso de Letras o status de formação contínua pode soar contraditório, já que a graduação é, oficialmente, o espaço privilegiado para a oferta da formação inicial, que promove a inserção dos futuros professores na nova profissão. No caso do curso de licenciatura em Letras-Inglês, a graduação é o momento em que se deve (ou se deveria) aprender o exercício do ofício de professor de Línguas e Literaturas e que, após a sua conclusão, a outorga do diploma de licenciado possa lhe proporcionar o gozo de todos os direitos e prerrogativas legais.

Como a formação de professores de Inglês é o tema central dessa discussão, levar em conta apenas os aspectos legais e/ou oficiais dessa formação limitaria qualquer investigação, especialmente a de professores de inglês. A questão é que a formação de professores no contexto brasileiro não acontece de forma tão linear como mencionei no parágrafo anterior, isto é, o vestibulando é aprovado no exame, inicia o curso de Letras sem experiência docente, aprende o(s) idioma(s) do(s) qual(is) será professor, estuda as disciplinas sobre ensino-aprendizagem de línguas, realiza o estágio, 
recebe o diploma e está pronto para atuar em escolas públicas e privadas, regulares ou livres.

Com a multiplicação de cursos de idiomas e a possibilidade de assumir aulas de inglês por meio de contratos temporários em escolas públicas e privadas, antes mesmo de concluir (ou iniciar) os cursos de graduação, alunos de Letras e também de outros cursos (Direito, Psicologia ou Administração, por exemplo) encontram, nesses empregos, algumas possibilidades: complementar a renda, fazer "bico", ocupar-se como professor ou aprender a profissão no sentido mais amplo, adquirindo experiência e inserindo-se no mercado de trabalho. Em cursos de idiomas, basta, muitas vezes, ter um inglês "fluente" e ministrar uma aula "legal" para se obter a vaga. Já em escolas regulares, públicas ou privadas, em muitos casos, é necessário estar, pelo menos, matriculado em um curso de licenciatura em Letras. A questão é, quando e como acontece a formação inicial desses professores e daqueles que, sem o diploma universitário de Letras, são registrados legalmente como instrutores de idiomas? Esses alunos-professores que decidem estudar Letras e já trazem experiência de ensino estão, de fato, em uma formação inicial? O que diferencia o curso de formação inicial de um curso de formação contínua?

Nesse sentido, entendo a formação de professores de Inglês como um processo que envolve o desenvolvimento profissional, não deve chegar ao fim, possui sempre objetivos em longo prazo e facilita a compreensão do professor sobre o seu ensino e sobre si mesmo como professor (VIAN JR, 2011). Essa formação, explica Cunha (2003), acompanha o tempo profissional dos sujeitos:

Apresenta formato e duração diferenciados, assumindo a perspectiva da formação como processo. Tanto pode ter origem na iniciativa dos interessados como pode inserir-se em programas institucionais. Neste último, os sistemas de ensino, universidades e escolas são as principais agências de tais tipos de formação. (CUNHA, 2003, p. 368).

Quando falo em formação, entendo-a, ainda, como oferecer as condiçôes necessárias para atuar nas mais diversas situações. Se falo em formação de professores, reconheço que ela precisa de reflexões e práticas sobre os seus contextos de atuação, tanto por meio do contato com alunos e situaçōes de aprendizagem, quanto por discussões, leituras, debates e olhares críticos acerca das perspectivas de ensino. Assim, formar é ser 
dotado de práticas que não podem ser desvinculadas de teorias, necessitam ser direcionadas, contextualizadas e voltadas a uma cultura específica (CHARLOT, 2005).

Ao falar em formação do professor de línguas estrangeiras, especialmente de inglês, é importante deixar claro, como explica Celani (2001), a existência de, pelo menos, dois tipos de formação²; um que envolve a aprendizagem e o outro que envolve o "treinamento". Ambos podem existir e coexistir em nossas escolas e são levados em consideração nesta pesquisa. A aprendizagem, de cunho reflexivo, está atrelada a uma visão de desenvolvimento e dá conta de questôes mais abrangentes da educação, com consequências sociais, pessoais, éticas, fundamentos dos métodos e currículos, tendo como cerne o ensino reflexivo e emancipatório; já o "treinamento", de cunho positivista, entende a profissão como técnicas aplicáveis universalmente a qualquer contexto de ensino-aprendizagem.

A ideia de discutir a problemática de alunos-professores já experientes que cursam Letras com habilitação em Inglês é provocada por vários motivos. As mudanças sociais e tecnológicas contribuíram bastante para a dificuldade em determinar quando começamos a atuar em nossas profissões. Não há uma linha que delimite esse espaço. É óbvio que um professor só assumirá uma vaga efetiva no serviço público se, no momento da posse, apresentar o seu diploma de licenciado. No entanto, como já enfatizei, a minha discussão vai além de questôes legais, pois há centenas de milhares de professores sem diploma atuando em escolas públicas no Brasil, como aponta matéria do site UOL Educação, a partir de um levantamento feito pelo Ministério da Educação. Segundo o site, há mais de 380 mil professores da educação básica matriculados em cursos superiores. Isso significa que seis a cada dez professores sem diploma estão em sala de aula buscando formação (UOL EDUCAÇÃO, 2011). Em outro levantamento, feito pelo Sindicato dos Professores do Ensino Oficial do Estado de São Paulo, em 2012, 80\% das escolas estaduais da cidade de Campinas possuem docentes sem diplomas. Segundo esse mesmo levantamento, em todo o estado de São Paulo, 4.355 dos 227 mil professores da rede estadual de ensino atuam sem diploma (G1CAMPINAS, 2012). Como se pode observar, a entrada de professores no mercado de trabalho antes mesmo de receberem os diplomas de licenciados

\footnotetext{
${ }^{2}$ Aprofundo adiante a discussão acerca das nomenclaturas utilizadas para tratar de formação docente.
} 
provam a não-linearidade dos acontecimentos. É nesse sentido que Hughes (1996), ao discutir as etapas da nossa vida profissional, reforça a necessidade de mais pesquisas sobre o assunto.

Posso afirmar que os alunos de Letras-Inglês atuantes em escolas como estagiários remunerados ou não remunerados e em cursos livres de idiomas sejam alunos-professores ou professores em formação. Dado o fato que estão em processo de aprendizagem do ofício na universidade, essa atividade é legitimada também por redes públicas estaduais e municipais de ensino, que os contratam com respaldo legal. Há, entretanto, alunos de outros cursos superiores, como Direito, por exemplo, que também ministram aulas de inglês (mas somente em cursos livres de idiomas) e que são igualmente chamados de professores pelos seus cursistas, legitimados pela posição que ocupam nessas instituiçõos. No entanto, legalmente, eles não são considerados professores, apenas atuam como tais em contratos de trabalho, cuja denominação instrutor de ensino ou instrutor de idiomas consta em suas carteiras profissionais de trabalho. Ser chamado de professor, nesse caso, é uma questão de status, termo explicado por Abbagnano (1998) como condição ou modo de ser, especialmente em sentido sociológico. Ele atua como professor, é chamado de tal em virtude da inserção em um ambiente educacional, mesmo que não tenha formação universitária.

Vale mencionar que, na universidade, o desempenho de alunos que já atuam como professores pode diferir da atuação dos seus colegas que ainda não possuem experiência docente, que ainda não tiveram a oportunidade de conseguir um contrato de trabalho em escolas públicas ou privadas, regulares ou livres. Os alunos-professores experientes já trazem às aulas da universidade saberes adquiridos pela prática diária com os seus alunos, já conhecem a organização curricular definida pelas escolas onde atuam e já estão se habituando ou já se habituaram aos problemas que precisam enfrentar quanto à condução dos conteúdos e para além deles. Para esses professores, o curso de Letras deixa de ser o primeiro contato com as particularidades da nova profissão e passa a ser um espaço de (re)construção dos seus saberes, da socialização dos saberes experienciais já existentes e a renovação dos saberes disciplinares trazidos pela universidade, agregando-os à experiência da sua prática de ensino. Nesse sentido, o curso de Letras, para esses alunos-professores experientes, deixa de ser o momento da formação inicial e passa a ter o status de formação contínua, tudo isso, indicado pelos seus posicionamentos, modos de pensar e agir diante da profissão. Tomando 
como base essa não-linearidade na formação do profissional de Letras, proponho um olhar em que unilateralidades são desfeitas. Para tanto, parto do pressuposto que o termo unilateral designa algo parcial, que expressa somente um lado ou um ponto de vista. Por essa razão, proponho desfazer essa unilateralidade, ou seja, defendo que a graduação pode ser entendida não necessariamente como um espaço de formação inicial, mas também como formação contínua.

De maneira geral, a formação de professores é levada em consideração tomando como base duas fases distintas, a formação inicial (ou pré-serviço) e a formação contínua (ou em serviço). Em ambos os casos, a universidade deve ser o local em que esses dois momentos são constituídos - não excluindo, obviamente, programas ou projetos de formação instituídos por secretarias municipais ou estaduais de educação -, em que alunos-professores, iniciantes ou não, devem enxergar as suas carreiras pelo prisma da integração entre o ensino, a extensão e a pesquisa. Perrenoud (2002) estabelece as principais diferenças entre os dois tipos de formação:

A formação inicial destina-se a seres híbridos, estudantes-estagiários que se tornarão profissionais. Ela deve formá-los para uma prática que, na melhor das hipóteses, está nascendo, ou foi sonhada. A formação contínua, por outro lado, trabalha com professores que estão exercendo sua função, que têm anos e mesmo décadas de experiência. (PERRENOUD, 2002, p. 20-21).

O autor reforça que a formação inicial é um ambiente em que a prática do professor precisa ser analisada, e a partilha de reflexóes sobre como se age, reage, decide e se comunica em sala de aula deve ser promovida. Nessa comparação, a diferença essencial reside no fato de que alguns ainda não exercem a profissão, ao passo que outros já possuem experiência. Nesse sentido, ambos estão engajados em programas que, a princípio, devem promover a (re)construção de saberes e identidades profissionais.

A questão é que nem sempre isso acontece. A maior queixa é que as licenciaturas não formam professores com preparo suficiente para enfrentar as novas demandas e a nova realidade da escola pública (GHEDIN et al., 2008; CELANI, 2010). Tal circunstância traz novas atribuições ao professor para além do trabalho com os seus alunos e os conteúdos das disciplinas que ele assume, como por exemplo, as condições de trabalho, a questão do tempo e das dificuldades, além das tensóes que elas geram nos professores. Muitos 
deles precisam se envolver a fundo no trabalho, que acaba tomando um tempo considerável da sua vida particular e dos seus fins de semana, como a preparação e correção de atividades e provas, atividades em sindicatos, clubes esportivos, cursos de aperfeiçoamento ou especialização ${ }^{3}$.

Para que os professores saiam preparados dos cursos de licenciatura, um dos aspectos a serem considerados são as aulas de Prática de Ensino, espaços privilegiados para o desenvolvimento de projetos que propiciem o conhecimento da realidade em que o futuro professor irá atuar (SZUNDI, 2009). Nesse contexto, a reflexão crítica sobre a sua própria prática e sobre as práticas dos professores e colegas de disciplina são o ponto de partida para que não exista mais o técnico, reprodutor de modelos, conhecedor e aplicador de regras gramaticais, com proficiência na língua estrangeira próxima à de um nativo, como descreve Moita Lopes (1996). Não estou afirmando que a proficiência e o conhecimento das regras gramaticais sejam dispensáveis, mas eles devem ser apenas parte integrante de uma formação mais abrangente, que dê conta de compreender e aprender a lidar com a tarefa complexa de ensinar inglês em escolas brasileiras. Segundo Gimenez (2005: 342), essa amplitude imprime um caráter "mais político, de comprometimento real com a defesa dos valores democráticos e justiça social." Se os formandos se enxergarem apenas como usuários da língua, eles poderão ser professores de inglês que simplesmente cumprem, e não muito bem, uma burocracia educacional.

Não obstante as orientações das diretrizes curriculares e sua aceitação pela maioria das instituições de Ensino Superior, é flagrante a "formação deficiente de professores, em faculdades sem qualidade que se proliferam pelo país" (CELANI, 2009, s.p). Nesse sentido, como muitos dos nossos professores de inglês ainda têm uma formação universitária precária, é na formação contínua que eles buscam saberes ainda desconhecidos do período de formação inicial, tentando reduzir possíveis defasagens. Não vejo graves problemas nessa busca, já que os professores necessitam entender a sua formação como um produto sempre inacabado, que deve estar em constante análise e reflexão. O contrário também pode acontecer, professores experientes, sem a graduação em Letras (que ensinam em institutos de idiomas, por exemplo) ou com a graduação em outras áreas buscam, no curso de Letras, a legitimação e a formação contínua como professores de inglês.

\footnotetext{
${ }^{3}$ Uma análise mais aprofundada acerca da carga de trabalho dos professores pode ser encontrada em Tardif e Lessard (2005).
} 
Por essa razão, acredito que nem sempre a formação inicial e a formação contínua ocorram de maneira tão linear quanto as suas nomenclaturas possam indicar. Como apontam Moita Lopes e Bastos (2010, p. 10), é o momento de se escapar da ótica do "somos isto ou aquilo", uma lógica, explicam os autores, "que se apoia na ideia de que há somente dois únicos lugares para se ocupar no mundo social, com diferenças bem marcadas e determinadas entre eles, e com um único espaço entre os dois que os demarca”. Essa perspectiva vai além de uma questão de identidade, procurando sentidos em espaços pouco claros, "em fronteiras, pessoas, ideias e fluxos que se entrecruzam" (idem). Para os autores, são possibilidades de fornecer novos caminhos para a compreensão da vida social, gerando outras possíveis visões e intepretaçõoes. No caso desta pesquisa, dos conceitos de formação inicial e formação contínua. Um professor cujo exercício da profissão docente ocorra concomitantemente com a graduação (essencialmente caracterizada como formação inicial) está, de fato, em uma formação contínua, pois já traz experiências prévias, não somente como aluno. Essa experiência anterior, que caracteriza a sua formação inicial, vem dos saberes baseados no trabalho cotidiano do professor e no conhecimento do seu meio ${ }^{4}$. Ele pode ter passado por cursos de formação, em muitos casos, denominados "treinamentos", que, apesar de não serem legitimados academicamente e possuírem um caráter tecnicista ${ }^{5}$, podem indicar vínculo com bases científicas e abordagens de ensino discutidas nesse processo ${ }^{6}$.

A esse respeito, Azambuja (2007), em tese de doutorado que discute a formação de professores no Rio Grande do Sul, entrevistou alunosprofessores que estavam em formação inicial e formação contínua e, em seu depoimento, uma das participantes, denominada Begônia, aluna da formação inicial que já atuava como professora, enfatizou a troca de

\footnotetext{
${ }^{4}$ Refiro-me ao que Tardif (2002) denomina "saberes docentes".

${ }^{5}$ Utilizo o termo tecnicista com base em Kincheloe (1997), que o entende como o domínio e a reprodução de técnicas de ensino pelo professor a partir do que é produzido por especialistas, sem haver a necessidade de refletir sobre o que se está fazendo.

${ }^{6} \mathrm{O}$ Instituto de Idiomas Yázigi, por exemplo, informa, em seu material didático utilizado na educação de professores pré-serviço, edição de 2005 , que a concepção de linguagem adotada pelo instituto é a sócio-histórico-cultural de Vygotsky. O mesmo material informa adotar a abordagem comunicativa e, como base metodológica das suas aulas, o task-based language teaching [ensino de línguas baseado em tarefas]. (YÁZIGI, 2005).
} 
experiências que acontece nos cursos de formação e assinalou a diferença entre ser aluno de graduação com e sem experiência docente:

Lá [no curso de graduação], acontece realmente a troca, porque tu vai estar me transmitindo conhecimento, mas eu vou estar te dizendo: ah, mas os meus alunos lá são assim, dá para se trabalhar dessa maneira assim!, o que não acontece quando o aluno que está fazendo a graduação não tem nem o conhecimento do que é uma escola... a educação formal é importante? É muito! Principalmente na sociedade do conhecimento, mas ela tem de transpor na prática, ela tem que servir para quê? Para ti avaliar tua prática e teu próprio conhecimento. (AZAMBUJA, 2007, p. 2-3).

O posicionamento da professora Begônia reforça que não há uma linearidade nos acontecimentos que se dão ao longo da carreira do professor. Antes mesmo de concluir a sua graduação, ela já atuava como professora das séries iniciais do Ensino Fundamental. É nesse contexto que ocorre o entrelace entre as formações inicial e contínua no ciclo das posições sociais, o que oferece à professora Begônia, matriculada em um curso de formação inicial, o status de aluna da formação contínua, graças às experiências legitimadas e incorporadas ao seu discurso pela prática docente.

Hepp (2008) fez um levantamento das várias terminologias para nomear a formação do professor que acontece em serviço. A autora esclarece:

Podemos ver as várias terminologias em vários contextos. Nos contextos anglo-saxônicos e latinos, encontramos: continuous education, continuing education, continuous formation e permanent training, em inglês; formation permanente, em francês; formación continua, formación permanente e educación permanente, em espanhol; e formação contínua e formação continuada, em Portugal e no Brasil. (HEPP, 2008, p. 29).

A minha opção pela terminologia "formação contínua" ao invés de "formação continuada", assim como Oliveira (2010), deve-se ao fato que, semanticamente, o termo "continuada”, denota algo que teve início e fim, já o termo "contínua" oferece a ideia de algo que está em constante realização. Morfologicamente, não há diferenças, ambos são adjetivos.

Antes da concepção de formação contínua ser entendida como um processo de desenvolvimento e constante realização, que ocorre ao longo de toda a vida profissional, outras quatro terminologias com diferentes concepções foram, e continuam sendo utilizadas, como explica Menezes (2003), a exemplo de reciclagem, treinamento, aperfeiçoamento e capacitação. 
O termo reciclagem, explica a autora, esteve presente principalmente na década de 1980, em ações de órgãos públicos e privados, envolvendo profissionais de diversas áreas, inclusive a educação. Nos últimos anos, essa terminologia é pouco utilizada na educação, já que vem sendo constantemente relacionada a processos de aproveitamento e modificação de objetos ou materiais; copos, papéis e garrafas, deixando de ser compatível com a ideia de atualização pedagógica.

O termo treinamento traz implícita a noção de automatismos, "no que tange ao treinamento de músculos ou de ações específicas e repetidas, treinamento de animais e modelagem de comportamento" (MENEZES, 2003, p. 314). No ensino de línguas estrangeiras, a ideia de treinar era forte com a abordagem estrutural e o método audiolingual, que surgiram, segundo Vieira-Abrahão (2010), no final da década de 1960 e início da década de 1970, quando ela mesma cursava Letras na Universidade de São Paulo:

Éramos treinados em técnicas para apresentação do diálogo, dos drills mecânicos de substituição, para a apresentação indutiva de gramática, para o desenvolvimento da leitura e, a partir do modelo, preparávamos nossas aulas. Quanto mais próximas do modelo fossem as nossas práticas, melhor a nossa avaliação nos estágios. (VIEIRA-ABRAHÃO, 2010, p. 225).

Muitos cursos livres de idiomas adotam, até os dias atuais, a perspectiva de treinamento, seja pelo método audiolingual seja pela releitura desse ou de outros métodos. Em vários casos, eles possuem um caráter prescritivo aos docentes, que devem seguir ou implementar os princípios a serem adotados nas aulas de línguas estrangeiras.

Com maior abrangência, o termo aperfeiçoamento, de acordo com Menezes (2003), envolve todos os aspectos do desempenho das funçôes docentes e evoca o sentido de completar ou acabar com o que estava incompleto e, ainda, adquirir maior grau de instrução ou aptidão. Pensa-se o aperfeiçoamento no sentido de "corrigir-se, abandonar alguns saberes, possibilitando a aquisição de outros" (idem, p. 315). Tem-se a impressão, acrescenta a autora, de que ações e pensamentos possam ser substituídos e que seria suficiente adquirir periódicos estoques de novas informaçôes e noções pedagógicas para aperfeiçoar os conhecimentos.

O termo capacitação também se constitui em torno dessa ideia de aquisição de "pacotes" de novas informações e teorias pedagógicas, que têm 
como objetivo tornar o professor "capaz de", "habilitá-lo" a alguma coisa. A adoção da concepção de capacitação pode ser entendida como a venda de ações e propostas fechadas, "aceitas acriticamente em nome da inovação e da suposta melhoria" (idem, p. 316). Este é um exemplo de concepções pedagógicas entendidas como um produto (algo a ser consumido) ao invés de serem entendidas como um processo.

Considerando essa discussão, entendo a formação de professores de inglês como um processo (e não um produto) de desenvolvimento profissional e pessoal, ocorra ele concomitantemente ou não a cursos originalmente caracterizados como formação inicial. Ela precisa envolver formadores e professores engajados em constante reflexão crítica sobre a própria prática, o que facilita a compreensão sobre si mesmo como professor, sobre o ensino, a escola, a linguagem e a sociedade. Um envolvimento que deve ser político, que defenda o acesso e a qualidade da aprendizagem de línguas de forma geral, e do inglês, em particular.

\section{A noção de Sentidos e Significados e os perfis dos participantes}

Como este trabalho tem a formação de alunos-professores de inglês com experiência como foco principal, acredito que exista a possibilidade de se verificar, nos sentidos e significados (VYGOTSKY, 1934/2010) atribuídos pelos participantes à formação que recebem, a presença de eventos psicológicos, institucionais, cotidianos e contradições resultantes do contato com o idioma e a cultura dos países de língua inglesa, bem como do contato com os alunos, pais dos alunos, formadores e coordenadores pedagógicos. Eles vão se produzindo, de acordo com Smolka (2004, p. 12), "no jogo das condiçỗes, das experiências, das posiçõos, das posturas e decisões desses sujeitos". Essa produção está associada às concepções de linguagem e ensino com as quais esse professor teve contato ao longo da sua vida, da sua formação e (re)construção da identidade profissional. Em minha concepção, essas informaçōes reforçam o status de formação contínua que pode ser atribuído ao curso de Letras-Inglês. Vygotsky (1934/2010) define sentido e significado assim:

[...] o sentido de uma palavra é a soma de todos os fatos psicológicos que ela desperta em nossa consciência. Assim, o sentido é sempre uma formação dinâmica, fluida, complexa, que tem várias zonas de estabilidade variada. O significado é apenas uma dessas zonas de sentido que a palavra adquire no contexto de algum discurso e, ademais, uma zona mais estável, uniforme e exata. (VYGOTSKY, 1934/ 2010, p. 465). 
O sentido parte, a princípio, do âmbito individual e, por isso, possui um caráter plural, dá margem a interpretaçôes, leituras, contradições, formas de conceber o mundo e os acontecimentos que se dão nele, sempre observando que eles são eventos enraizados em aspectos sociais, culturais e históricos. Os diferentes eventos psicológicos dos indivíduos, nesse sentido, são despertados por suas diferentes histórias, o que proporciona maior fluidez e maior instabilidade às palavras, fazendo com que a atenção ao contexto seja necessária. O significado, por sua vez, parte do âmbito coletivo, socialmente estabelecido, daí o seu caráter generalizador, que oferece menor fluidez e maior estabilidade às palavras, mesmo que essa estabilidade seja temporária, já que a língua é dinâmica e está em constante processo de mudança.

Há nesse caso, uma relação tão estreita que, dificilmente, pode-se pensar em separar sentido de significado e vice-versa. Como esses conceitos têm base na teoria sócio-histórico-cultural, Liberali (2009, p. 105) esclarece que o sentido não é único e exclusivamente individual, já que os nossos eventos psicológicos são construídos a partir da relação com os outros. Por isso, o sentido também pode ser visto como uma influência social no indivíduo, "como a maneira pela qual os significados são internalizados e externalizados por cada indivíduo"; já o significado reflete "uma produção social convencional por meio dos quais os seres humanos apropriam-se de produções das gerações anteriores". Por essa razão, não há como atribuir sentido sem a contribuição do que é socialmente definido e não há como atribuir significado a eventos que não fazem parte da consciência individual.

Optei por utilizar entrevistas semiestruturadas a partir das orientações metodológicas de Lüdke e André (1986) e Rizzini (1999). Esses autores explicam que não há, nesse tipo de entrevista, uma sequência rígida para fazer as perguntas, e a grande vantagem com relação a outras técnicas está na captação mais rápida e corrente da informação desejada, tanto com relação à diversidade dos perfis dos participantes quanto à variedade dos tópicos.

Os excertos das entrevistas que apresento aqui trazem respostas às seguintes perguntas; "O que é formar um professor de inglês?"; "Conta como foi o seu período de estágio"; "O que tem sido mais produtivo aqui no curso de Letras?"; "Quais são as necessidades profissionais do professor de inglês?"; "Para que serve o curso de Letras?"; e "Que disciplinas ajudaram em sua formação como professor?".

Os perfis dos participantes desta pesquisa estão descritos a seguir. Eles são graduandos em Letras, com habilitação em Inglês, em uma Universidade 
Federal da Região Nordeste do Brasil. A eles foram atribuídos nome fictícios com o intuito de preservar as suas identidades.

Ellen

A aluna-professora Ellen tem 23 anos e cursou toda a Educação Básica em uma escola privada. Concluiu o Ensino Médio em 2007 e, em 2008, iniciou o curso de Letras, com habilitação em Português-Inglês. Na mesma época, começou a ensinar inglês em um curso de idiomas. No momento da coleta de dados, era professora dessa mesma instituição e em uma escola regular da rede privada, voltada apenas para a Educação Infantil e o Ensino Fundamental I.

Justin

O aluno-professor Justin tem 42 anos e cursou toda a Educação Básica em uma escola pública. Concluiu o Ensino Médio em 1988 e começou a ensinar Inglês, em 1991. Primeiramente, formou-se em Pedagogia e, só em 2006, iniciou o curso de Letras, com habilitação em Português-Inglês. Antes de cursar Letras, Justin já havia se formado em Pedagogia. É professor efetivo em uma escola da Rede Municipal e atua como professor das séries iniciais do Ensino Fundamental. Já ensinou inglês nesta mesma escola durante dois anos.

Kate

A aluna-professora Kate tem 23 anos e cursou toda a Educação Básica em uma escola privada. Concluiu o Ensino Médio em 2007 e, em 2008, iniciou o curso de Letras, com habilitação em Português-Inglês. Começou a ensinar inglês quando estava no quarto semestre de Letras e ainda não havia cursado as disciplinas de formação. No momento da coleta de dados, atuava como professora em um curso livre de idiomas e nunca atuou em escolas regulares.

Patrick

O aluno-professor Patrick tem 26 anos e cursou toda a Educação Básica em uma escola privada. Concluiu o Ensino Médio em 2004, em 2005 começou a cursar Engenharia Química, mas em 2007 resolveu prestar novo 
vestibular, dessa vez para Letras, com habilitação em Inglês. No ano anterior ao segundo vestibular, em 2006, Patrick havia começado a dar aulas de inglês. No momento da coleta de dados, era professor em um curso livre de idiomas e já havia atuado durante um ano em uma escola regular da rede privada.

\section{A formação do professor de inglês sob a ótica dos participantes}

A experiência que a aluna-professora Kate possui é como professora de um renomado curso livre de idiomas brasileiro, que lhe rendeu a participação em "treinamentos", idas a congressos promovidos por esse curso e o incentivo em realizar exames de proficiência, nos quais foi aprovada com pontuações satisfatórias. $\mathrm{Na}$ entrevista, ela mencionou algumas diferenças entre o ambiente de "treinamento" ao qual já estava acostumada e o ambiente de formação encontrado na universidade. Ao ser questionada sobre o que seria formar um professor de inglês, ela enfatizou que existe a possibilidade de alguém sem o diploma universitário ser um bom professor de inglês, isto é, ser formado é muito mais do que ter um diploma em mãos:

Pesquisador: Para você, o que é formar um professor de inglês?

Kate: É difícil de responder. $O$ ato de formar não significa que a pessoa seja um professor. Ela não vira um professor porque tem o diploma. Você pode ter o diploma e ser um professor péssimo. Vocêpode ser um professor muito bom e não ter formação nenhuma. (ENTREVISTA COM KATE, grifos meus).

Kate atribui à formação do professor sentidos e significados que priorizam a prática em sala de aula, ao mesmo tempo em que valorizam o conhecimento acerca de questôes sobre o ensino-aprendizagem, quando afirma que "o ato de formar não significa que a pessoa seja um professor". Ao dizer, "você pode ser um professor muito bom e não ter formação nenhuma", ela acredita que a formação possa ser adquirida pelo contexto em que atua. No curso de idiomas, o "como fazer" predomina sobre "os estudos acerca do como fazer". Nessas instituições, onde um diploma de Letras pode não significar muita coisa, o que conta é aprender a ministrar uma boa aula e satisfazer os alunos.

Apesar de valorizar a prática e "preferir tê-la", como afirmou no excerto anterior, Kate garante ter aprendido bastante com as disciplinas de 
Metodologia do Ensino de Inglês na Universidade e se lembra muito bem de como foi a experiência:

Pesquisador: $\mathrm{O}$ que tem sido mais produtivo aqui no curso de Letras para você?

Kate: Mais produtivo? Então, tem muitos professores que realmente têm algo pra mostrar e fazer a gente pôr a mão na massa e tal, como Metodologia, que a gente teve que dar aula de cada método. Então, a gente entrou em contato com todos os métodos, não foi só uma leitura. A gente sentiu um pouco de como era cada aula daquela. As aulas de língua inglesa eu não posso dizer que eu aproveitei muita coisa porque, como eu já disse, sempre era aquela coisa de eu estar um nível acima e ter sempre que calar mais do que participar. Eu só participava quando o professor pedia. Eu aprendi muito nas matérias de Metodologia, gostei muito de Ensino de Fonética também porque é uma coisa que ninguém sabia como trabalhar ou se trabalhava realmente. Parece sem importância, mas quando a gente estuda, a gente descobre que precisa saber pra poder falar melhor.

Pesquisador: Conte mais como essas disciplinas ajudam em sua formação. Kate: Assim, apesar de Metodologia não ser uma matéria de prática, ser uma matéria mais teórica, a professora conseguiu transformar ela em prática, fazendo com que a gente apresentasse microaulas. Então, por mais que a gente tivesse certeza de como dar aquela aula, ia ter outra turma apresentando outra aula do mesmo método, então a gente podia comparar, criticar, ver como funcionava, adaptar, saber se aquele método serviria pro nosso contexto e tal [...]. (ENTREVISTA COM KATE, grifos meus).

Kate atribuiu às disciplinas de Metodologia do Ensino de Inglês sentidos e significados inerentes a sua prática como professora, que não teve contato com métodos de ensino de inglês apenas na Universidade como também no curso de idiomas onde atua. O "contato com outros métodos", por meio das aulas de Metodologia, como informou, proporcionou a ela a tomada de consciência de novas possibilidades de ensinar inglês, do aperfeiçoamento das práticas docentes características de cursos de formação contínua na universidade ao seu contexto de atuação.

Os sentidos e significados que Patrick atribui à formação de professores e ao curso de Letras têm relação com a aprendizagem da língua e a aprendizagem de como ensiná-la de forma que ambos os movimentos 
aconteçam de forma integrada. Para ele, o ideal é aprender o idioma já sendo conscientizado da sua prática de ensino, e não de forma hierarquizada (primeiro a língua e depois a metodologia), como se pode observar no excerto a seguir:

Pesquisador: Para que serve o curso de Letras?

Patrick: Eu acho que eu diria que o curso de Letras serve pra você aprender a dar uma aula. Pelo que eu vivenciei. Grande parte dos professores que eu tive de Língua Inglesa I, II, III, IV, eles não ensinaram basicamente a ensinar inglês, eles ensinaram algumas coisas de gramática, usos da língua, em separado, sabe?

Pesquisador: E você sentiu falta disso?

Patrick: Ahan, de integrar.

Pesquisador: O que é formar um professor de inglês?

Patrick: Hum...formação?...Eu penso em tanta coisa aqui. Eu penso o seguinte: nos aspectos que uma formação deve ter, você ter conhecimento do que vai ensinar, o que quer que seja, matéria tal, no nosso caso, conhecimento da lingua e ter conhecimento da maneira como você vai ensinar, de teorias e práticas pedagógicas, por exemplo. (ENTREVISTA COM PATRICK, grifos meus).

Esses sentidos e significados têm relação com o que propõem as diretrizes do Conselho Nacional de Educação (BRASIL, 2002); as disciplinas devem conter componentes práticos e eles não devem ficar restritos apenas ao estágio ou desarticulados do restante do curso, como o aluno-professor reclamou, ao dizer "eles não ensinaram basicamente a ensinar inglês, eles ensinaram algumas coisas de gramática, usos da língua, em separado, sabe?". A aprendizagem da língua e a aprendizagem do ensino dela devem estar presentes do começo ao fim do curso, permeando toda a formação do professor (BRASIL, 2002). No currículo de Letras estudado por Patrick, há oito disciplinas de Língua Inglesa ${ }^{7}$, e as disciplinas de Metodologia do Ensino de Inglês só começam a ser ministradas no $5^{\circ}$ semestre letivo. Esse adiamento pode fazer com que o aluno de Letras tenha baixa identificação

\footnotetext{
${ }^{7}$ Para as disciplinas de Língua Inglesa, o curso de Letras com habilitação em Inglês adota o material didático Global (CLANDFIELD e BENNE, 2011), das Línguas Inglesas I a VI, e o American Inside Out (JONES e BASTOW, 2007) nas Línguas Inglesas VII e VIII.
} 
com a profissão, podendo concebê-lo apenas como um curso de idiomas. Daí talvez um dos motivos pelos quais muitos vestibulandos procuram cursos de Letras com habilitaçóes em línguas estrangeiras para aprenderem uma nova língua e, no caso de uma universidade federal, sem custos. Isso também reduz ou elimina o caráter político dessa formação. Atuar de modo mais incisivo com vistas a construir a identidade do professor de inglês já no início no curso é o caminho, e isso precisa começar pela revisão dos currículos, como apregoam as diretrizes, e se concretizar na sala de aula e para além dela. (GIMENEZ, 2005).

Patrick afirmou que o curso de idiomas onde trabalha adota a abordagem comunicativa e o task-based language teaching [ensino de línguas baseado em tarefas] como bases teórico-metodológicas. Quando perguntei sobre as disciplinas que o ajudaram em sua formação, ele logo se lembrou de Didática e Metodologia do Ensino de Línguas, ministradas respectivamente pelos Departamentos de Educação e Letras Vernáculas, como pode ser observado no excerto abaixo:

Pesquisador: Quais foram as disciplinas que você considera que te ajudaram em sua formação como professor?

Patrick: Eu gostei...da carreira de professor? É...eu acho que a que eu gostei mais foi uma de Metodologia do Ensino de Linguas, que...porque eu vi assuntos que eu mais sentia falta, menos especificos. Gostei muito dessa disciplina.

Pesquisador: O que você aprendeu nela?

Patrick: Eu estou me lembrando de Didática também... Na época, eu estava lendo... a professora passou Dermeval Saviani e outro livro que tinha vários autores, um livro organizado.

Pesquisador: Nessas aulas as discussões eram sobre a educação de forma geral ou especificamente sobre o ensino de inglês?

Patrick: Não, era sobre questões mais gerais. (ENTREVISTA COM PATRICK, grifos meus).

O interesse pelas disciplinas que discutem aspectos mais abrangentes $\mathrm{da}$ área de Educação confere a Patrick a postura de aluno de formação contínua, que procura articular os saberes já adquiridos pela experiência com os saberes disciplinares da Educação, representados, como ele mesmo apontou, pelas disciplinas de Didática e Metodologia do Ensino-aprendizagem de Línguas. 
Uma queixa evidente na entrevista com Justin refere-se à falta de condições materiais para trabalhar. Em seus sentidos e significados, formar professores quer dizer dotá-los de condições para o manuseio de recursos tecnológicos. Com isso, há o sucesso no ensino-aprendizagem de inglês. Ao ser indagado quanto às necessidades profissionais do professor de inglês, ele é categórico ao trazer o assunto à discussão:

Pesquisador: Quais são as necessidades profissionais do professor de inglês?

Justin: Todas. Quando eu digo todas...é...se formos analisar a rede pública em especial onde eu tenho experiência, o descaso é grande. Nós não temos recursos para trabalhar em nenhuma matéria, e em especial a língua inglesa, que é vista como algo que tá ali só pra encher linguiça, pra tapar um buraco na grade.

Pesquisador: O que falta de recursos pra você ensinar inglês?

Justin: Eu acho que falta...bem, um bom material, uma estrutura, sinceramente o meu sonho como professor de inglês é ter uma estrutura, algo similar a um cursinho de inglês, ter um local, meu sonho seria assim: quem quiser estudar inglês não seria por obrigação. Perguntar, quem quer estudar inglês? Aí separaria os alunos e colocaria naquele local, naquela sala, aí teria um material bom pra trabalhar, né? Deveria ter tudo, fones de ouvido, microfones, ter...computadores, ter o melhor possivel pra trabalhar como muita escola de inglês tem. Então, meu sonho como professor de inglês é esse, ter uma estrutura. (ENTREVISTA COM JUSTIN, grifos meus).

$\mathrm{Na}$ fala do professor Justin, a falta de recursos materiais para o trabalho e o sonho de que a sua escola possa lhe oferecer a estrutura existente em cursos de idiomas. Para ele, não ter esses recursos para trabalhar revela descaso do poder público para com as escolas. Ao solicitar mais detalhes sobre os recursos que faltam em sua escola, ele reivindica os materiais que podem ser encontrados em laboratórios de línguas, dentre eles, os computadores.

Quando se fala em tecnologia, logo o computador é lembrado. Em muitos casos, esquece-se que, antes dessa máquina ser criada, sempre tivemos à disposição as mais variadas ferramentas tecnológicas para facilitar o nosso dia a dia - a exemplo da lousa, o livro didático e o giz, presentes há, pelo menos, um século no campo educacional. Para que as ferramentas 
tecnológicas sejam inseridas nesse meio, é necessário muito mais do que a simples introdução de computadores e smart boards [lousas eletrônicas] em laboratórios. No caso da escola do professor Justin, a situação é ainda mais restrita, há apenas a lousa, o giz e o livro didático como recursos tecnológicos.

A fim de suprir essa necessidade, é importante observar que há mais de 15 anos, no Brasil, muitas escolas (e não é o caso da escola de Justin) já vêm recebendo laboratórios de informática, e existem programas de capacitação nessa área, como é o caso do Programa Nacional de Informática na Educação (ProInfo). Entretanto, seria necessário verificar como esses cursos estão sendo ministrados, se há participação efetiva de professores e demais envolvidos no processo educacional e se a capacitação está sendo suficiente para que o computador seja, de fato, introduzido nas práticas de sala de aula. Isso quer dizer que o professor precisa não somente de máquinas, ferramentas e cursos de capacitação, é necessário estar ciente dos seus objetivos de ensino e da análise das necessidades dos seus alunos com relação à disciplina que ministra. Como lembra Ligouri (1997, p. 91, grifo da autora), "para obter efeitos com as tecnologias não fazem falta apenas computadores e programas". Entra em discussão o papel do professor e as questôes culturais que emergem em sala de aula. A meu ver, a tecnologia em si não faz a diferença, e sim o uso que se faz dela.

Nos sentidos e significados atribuídos à formação pela aluna-professora Ellen, pude perceber, ao longo de toda a entrevista, que ela entende a universidade como um lugar que pouco a ajuda em sua formação, não necessariamente por causa dos professores e conteúdos, mas pelas circunstâncias em que as disciplinas ocorrem. Ao questioná-la acerca do estágio supervisionado e as contribuições dele para a sua formação, ela afirmou não ter tido contato suficiente com a escola-campo como gostaria:

Pesquisador: Conta como foi seu período de estágio.

Ellen: Não foi. O primeiro estágio...é... eu não fiz o Estágio I porque eu já tinha um ano de experiência no Ensino Fundamental e eu peguei dispensa. E o Estágio II, as escolas estavam em greve por tempo indeterminado, então ficou um acordo que a gente ia fazer uma pesquisa, um artigo, na verdade... que a gente ia desenvolver um artigo, a gente preparou um questionário e desenvolveu um artigo. Então, eu não fui à sala de aula pelo estágio de inglês na universidade. (ENTREVISTA COM ELLEN, grifo meu). 
Uma Resolução do Colegiado do Curso de Letras investigado dispensa do Estágio Supervisionado, por meio de declaração ou contrato de trabalho, o aluno que comprove atividade docente no nível de ensino relacionado ao Estágio, isto é, o Estágio Supervisionado em Inglês I é para a prática docente no Ensino Fundamental II, e o Estágio Supervisionado em Inglês II é para a prática docente no Ensino Médio. Ellen foi dispensada do Estágio Supervisionado I por ter experiência comprovada no Ensino Fundamental II. Já a sua experiência no Ensino Médio não pôde ser concretizada em virtude de uma greve de professores da Rede Estadual, deflagrada em 2012. A nota do Estágio Supervisionado II foi atribuída à escrita de um artigo científico ${ }^{8}$.

Entra em discussão aqui as atividades práticas que, em tese, devem permear toda a formação do professor e já são preconizadas pelas diretrizes CNE/CES 492/2011 (BRASIL, 2002) do Conselho Nacional de Educação para os cursos superiores há mais de uma década. Entendo como atividades práticas não somente ir às escolas e assumir salas de aula de inglês, mas, como afirma o artigo 13 dessa mesma diretriz: "A coordenação da dimensão prática transcenderá o estágio e terá como finalidade promover a articulação das diferentes práticas, numa perspectiva interdisciplinar" (BRASIL, 2002, p. 66-67). Entretanto, é necessário discutir o que se entende por "diferentes práticas" e se elas estão sendo levadas em consideração na formação dos professores. Essas práticas referem-se a questóes relacionadas ao ofício do professor, como preparação de aulas, desenvolvimento de projetos pedagógicos, compreensão do funcionamento da escola como uma estrutura coesa e coerente? O que significa o fato da aluna-professora Ellen não ter tido experiência em escolas do Ensino Médio, apesar de ter passado quatro anos em um curso que, prioritariamente, deveria prepará-la para isso? $\mathrm{Na}$ universidade investigada, os Estágios Supervisionados em Inglês existem em apenas dois semestres, no $7^{\circ}$ e no $8^{\circ}$, reduzindo assim, as possibilidades de contato com a realidade das escolas públicas de ensino, já que greves, paralisaçôes, datas comemorativas, dentre tantos outros imprevistos são uma constante no cotidiano das escolas públicas brasileiras.

Em outro momento da entrevista, Ellen reforça que a universidade não proporcionou o contato com a realidade do ensino nas escolas públicas,

\footnotetext{
${ }^{8}$ Não investiguei as razões pelas quais a prática docente no Ensino Médio tenha sido substituída pela escrita de um artigo científico. Acredito que se trata de um critério de avaliação adotado pela professora supervisora de estágio e vai além dos objetivos desta pesquisa.
} 
tão necessário ao professor em formação:

Pesquisador: $\mathrm{O}$ que tem sido mais produtivo pra você aqui no curso de Letras?

Ellen: Para mim não foi o estágio de Língua Inglesa. Português sim. Agora, de Língua Inglesa não foi muito produtivo porque, além de não ter sido bem um estágio, eu achei mais confortável trazer as minhas experiências pra cá do que fazer uma coisa que não tinha a ver com a realidade. Mas, na verdade, você aprende na universidade que vai ser aquele negócio bonito e que os alunos vão aprender e que você vai conseguir dar aula para 50 alunos numa turma, que você vai conseguir ensinar inglês e, na verdade, não é. Você não consegue passar, ensinar inglês numa turma de 50 alunos, numa escola pública, onde, às vezes, você não tem nenhuma estrutura de sala para poder trabalhar direito. (ENTREVISTA COM ELLEN, grifo meu).

A universidade não proporcionou a Ellen o contato com a docência de inglês nas escolas públicas. Ele teve apenas a oportunidade de observar aulas na disciplina de Estágio Supervisionado Geral. Toda a sua experiência é em contextos diferentes - um curso de idiomas e uma escola privada regular de Ensino Fundamental. Mesmo assim, houve, da parte dela, a tentativa de acrescentar a sua experiência de professora da rede privada as mais diversas possibilidades de lidar com as dificuldades encontradas no cotidiano da escola. Ao dizer que, nas aulas de Estágio Supervisionado, percebia discussōes "que não tinham nada a ver com a realidade", como grifei no excerto, notase uma característica de professora engajada em formação contínua que, a partir das suas experiências, busca ressignificar a atividade docente e refletir acerca de questôes reais ao invés de recebê-las prontas como possibilidades de trabalho com situações ideais. Ela demanda, na graduação, diferentemente dos seus colegas que não têm experiência, um espaço característico de formação contínua, que a ajude a desenvolver uma formação crítico-reflexiva a partir da compreensão do contexto escolar, social e histórico, como explica Ramos (2010),

Essa formação [contínua], por sua vez, demanda um espaço de reflexão, no qual os envolvidos poderão analisar, discutir e avaliar suas práticas à luz de próprio agir e de teoria sobre ensino-aprendizagem, sobre linguagem e no qual, ambas, prática e teoria, possam ser confrontadas, 
(re)compreendidas e (re)construídas, encaminhando transformações quando e onde se fizerem necessárias. (RAMOS, 2010, p. 59).

O estágio supervisionado na universidade foi, para Ellen, algo distante da realidade. A avaliação e as discussões sobre as ações à luz da relação teoria e prática, de que trata Ramos, não foram possíveis em virtude de uma série de impedimentos enfrentados pela aluna-professora em seu contexto. Esses impedimentos vão desde o currículo do curso - que limita a dois a quantidade de estágios supervisionados - às greves que trazem consigo a escrita de artigos científicos, substituindo a Prática de Ensino. Essas ações geram incoerências entre aquilo que se vê na universidade e o que o professor de inglês encontra no momento em que assume a sala de aula.

\section{Considerações finais}

Os participantes atribuíram sentidos e significados referentes a uma formação em que teoria e prática não são entendidas como unidade, há um distanciamento entre esses dois elementos e esse distanciamento é atribuído ao número reduzido de disciplinas de formação, à pouca relação entre as disciplinas que compóem a matriz curricular do curso de Letras em que estão matriculados e às poucas oportunidades de contato com escolas-campo para realizarem o estágio supervisionado. Eles reivindicam, em suas falas, o que as diretrizes curriculares para a formação de professores já sugerem desde 2002: mais contato com a realidade das escolas, mais reflexão sobre a prática, melhor visualização de questões práticas nas disciplinas ditas teóricas. Por enquanto, para eles, a formação tem sido entendida como o excesso de abstração e poucas experiências reais com a profissão. Isso se torna ainda mais evidente (e por que não dizer ainda mais sério?) por se tratar de professores que já conhecem a rotina de uma sala de aula. Para eles, mesmo tendo conhecimento da realidade do ensino de inglês, são poucas as oportunidades de discutir sobre ele e ter contato com ele a partir da universidade.

Para os participantes, as "receitas" de como ensinar, as palestras e os conteúdos sobre "como fazer" são sentidos e significados fortemente atribuídos à formação de professores de inglês. Isso é justificado pela aceitação de colegas não graduados em Letras que atuam em escolas de idiomas, ao afirmarem que, "eles sabem o inglês e eles dão uma aula legal" porque participaram dos "treinamentos", receberam dicas de como ensinar. Em alguns momentos, as perspectivas de formação críticas podem ser lembradas, muitos afirmam 
sentir falta delas, mas, para eles, se há "fórmulas ideais" para aprender a profissão de professor, a formação ocorre.

Por essa razão, há sentidos e significados que priorizam e atribuem maior valor à prática em detrimento da teoria. Nesse sentido, formar-se professor é possuir "práticas". A justificativa é que os professores que "falam" o idioma e sabem ministrar uma "boa" aula serão mais facilmente contratados por cursos de idiomas. Nota-se, nessa concepção, a ideia de que aprender uma língua é aprender a falar essa língua. Atribui-se maior valor às habilidades de pronúncia, compreensão e expressão orais, e menor valor às outras habilidades (ler e escrever) ou, ainda, à integração dessas habilidades.

Esses resultados reforçam a ideia de que o curso de Letras-Inglês pode ter o status de formação contínua e responde a pergunta que dá título a este artigo "Por que a graduação em Letras-Inglês pode ter o status de formação contínua?". Sendo o status uma condição, um modo de ser ou uma situação, entendo que o curso de Letras, com habilitação em Inglês seja para Justin, Patrick, Ellen e Kate um curso de formação contínua e não de formação inicial, assim como o seja para tantos outros Justins, Patricks, Ellens e Kates, alunos-professores experientes e matriculados em cursos de licenciatura em Letras pelo Brasil. As razóes pelas quais acredito poder atribuir um status, que, em alguns casos, possa ser interpretado como contraditório, reside nos argumentos que passo a discutir agora.

Vale enfatizar, antes de tudo, que a atribuição do status de formação contínua ao curso de Letras, neste caso, deve-se à ampliação para além da ideia de identidade, proposta por Moita Lopes e Bastos (2010, p. 10-11). Para esses autores, não mais existem dois únicos lugares para se ocupar no mundo social, com diferenças bem marcadas e determinadas entre eles. No caso desta pesquisa, formação inicial e formação contínua. Essa lógica rejeita "binarismos identitários" e coloca sob análise "processos de hibridação, de ambivalência e de ambiguidade, dentre outros", procura sentidos em ideias que se entrecruzam e se misturam. A meu ver, essa forma de olhar a formação de professores na atualidade parece ser mais adequada "ao mundo de barreiras e limites porosos em que vivemos". (idem).

Listo abaixo alguns argumentos que ajudam a atribuir ao curso de Letras o status de formação contínua para alunos-professores experientes matriculados nele, rejeitando uma possível unilateralidade da formação inicial do professor de inglês, isto é, entrecruzando, misturando e hibridizando as suas características: 
- Os alunos-professores, por possuírem experiência de ensino, contribuem, ao participar das disciplinas, na universidade, com reflexões mais concretas e sistemáticas acerca dos processos de ensinar e aprender inglês, conduzindo-se e conduzindo os colegas ao aperfeiçoamento profissional, tendo a figura do formador como mediadora dessa experiência.

- Independente do contexto em que atuem - escolas regulares ou institutos de idiomas - os alunos-professores experientes sempre possuem os saberes da experiência, maneiras pessoais de ensinar, "macetes" da profissão e traços da personalidade profissional. Ao cursar as disciplinas na universidade, esses alunos possuem posicionamentos diferenciados daqueles que ainda não tiveram a oportunidade de ensinar inglês.

- As disciplinas que discutem metodologias do ensino de línguas estrangeiras oferecerão leituras e releituras das concepções de métodos de ensino, proporcionando aos alunos-professores experientes possibilidades de trabalho para além daquelas a que a sua escola, regular ou de idiomas, é afiliada.

- O fato de já possuírem experiência, aliado à formação crítica que a universidade busca oferecer, proporciona aos alunos-professores experientes a possibilidade de lançar olhares críticos não só às perspectivas de ensino adotadas nas escolas onde trabalham como também ao currículo da universidade onde estudam.

- Alunos-professores experientes têm mais facilidade em identificar teorias e práticas que não se adaptam ao seu contexto, filiando-se ao argumento de Prabhu (1990) que, não se trata de diferentes contextos utilizarem diferentes métodos, mas que o mesmo contexto deve utilizar diferentes métodos ou partes de diferentes métodos.

- Mesmo havendo momentos em que a universidade não ajuda a relacionar teoria e prática, alunos-professores experientes têm consciência de que precisam refletir sobre a prática e sobre o papel da universidade no incentivo a essa reflexão, como mostrei em vários excertos ao longo da análise de dados. Trata-se de uma postura de alunos engajados em formação contínua.

Vale ressaltar que esses argumentos relacionam-se aos resultados desta investigação. Eles mesmos podem ser reformulados ou adaptados, outros 
podem ser acrescentados, mas precisam levar em conta a complexidade em que professores formadores e alunos (com ou sem experiência) estão envolvidos em um curso de Letras, um espaço de heterogeneidade, em que a reflexão sobre o ensino-aprendizagem de inglês deve prevalecer, já que se trata de um contexto envolto em limitaçôes, restrições, desafios e possibilidades que devem ser observadas enfrentadas e avaliadas constantemente.

Reforço que o curso de Letras recebe o status de formação contínua apenas quando há alunos experientes matriculados nele. Trata-se de sinalizar que os tempos de que "somos isto ou aquilo" (MOITA LOPES e BASTOS, 2010) deixaram de existir, é a lógica da outridade/ alteridade, conceitos que ganham espaço para discussão em várias áreas do conhecimento, inclusive na Linguística Aplicada. Estar atento a essa concepção é perceber movimentos não lineares ou não regulares em nossas vidas, em nossa formação e em nossa profissão. Considerar a graduação em Letras-Inglês como espaço de formação contínua é entender que ela não seja, necessariamente, formação inicial. E ainda, é priorizar, antes de tudo, a ideia de formação, em seu sentido mais amplo, completo e complexo que ela possa denotar. É desfazer unilateralidades.

\section{Referências}

ABBAGnANO, N. Dicionário de Filosofia. São Paulo: Martins Fontes, 1998.

AZAMBUJA, G. Os processos formativos da docência e suas implicaçôes na prática pedagógica: cultura(s), representações e saberes. 289f. Tese (Doutorado em Educação). Universidade do Vale do Rio dos Sinos-UNISINOS, São LeopoldoRS, 2007.

BRASIL. Conselho Nacional de Educação. Diretrizes Curriculares Nacionais para a Formação de Professores da Educação Básica, em nivel superior, curso de licenciatura, de graduação plena. Brasília: MEC/CNE, 2002.

CELANI, M. A. A. Perguntas ainda sem resposta na formação de professores de línguas. In: GIMENEZ, T; MONTEIRO, M. C. G. (Orgs). Formação de professores de Linguas na América Latina e Transformação Social. Campinas: Pontes, p. 57-67, 2010.

CELANI, M. A. A. Projeto de Pesquisa: Tensões na tarefa do formador/educador em um contexto de formação contínua de professores de inglês da escola pública: para uma compreensão da prática na construção do conhecimento crítico-pedagógico. LAEL/PUC-SP. 2009. Disponível em: <http://pos.pucsp.br/lael/areapesquisas>. Acesso em: 27 jan. 2013. 
CELANI, M. A. A. Ensino de Línguas Estrangeiras: ocupação ou profissão? In: LEFFA, V.J. (Org.). O Professor de Linguas Estrangeiras: construindo a profissão. Pelotas-RS: Educat, p. 21-40, 2001

CHARLOT, B. Relação com o saber, Formação de Professores e Globalização: questôes para a educação hoje. Porto Alegre: Artmed, 2005.

CLANDFIELD, L.; BENNE, R.R. Global: Coursebook. MacMillan, 2011.

CUNHA, M. Formação continuada. In: MOROSINI, M. C. et al. (Orgs). Enciclopédia de Pedagogia Universitária. Porto Alegre: FAPERGS/RIES, 2003.

GHEDIN, et al. (Org.). Formação de Professores: caminhos e descaminhos da prática. Brasília-DF: Liber Livro, 2008.

GIMENEZ, T. Currículo e Identidade Profissional nos cursos de Letras/ Inglês. In: TOMICH et al. (Orgs). A Interculturalidade no Ensino de Inglês. Florianópolis: ARES, 2005.

G1 Campinas e Região. Campinas tem $80 \%$ das escolas estaduais com docentes sem diploma. g1.globo.com. 2012. Disponível em: <http://g1.globo.com/sp/campinasregiao/noticia/2012/09/campinas-tem-80-das-escolas-estaduais-com-docentes-semdiploma.html.> Acesso em: 5 nov. 2013.

HEPP, I.C.U. A Formação continuada na escola: treinar para reproduzir ou formar para transformar. 203f. Dissertação (Mestrado em Educação). Universidade Federal de Santa Maria - UFSM. Santa Maria-RS, 2008.

HUGHES, E. Carrières, cycles et tournants de l'existence: Le regard sociologique. Essais choisis. Paris: Editions de l'École des Hautes Études en Sciences Sociales, 1996.

JONES, C.; BASTOW, T. American Inside Out: student's book. MacMillan: Oxford, 2007.

KINCHELOE, J. L. A formação do professor como compromisso político: mapeando o pós-moderno. Tradução de Nize Maria Campos Pellanda. Porto Alegre-RS: Artmed, 1997.

LIBERALI, F. C. Creative Chain in the Process of Becoming a Totality. In: Bakhtiniana, São Paulo, v.1, n. 2. p.100-124, 2009.

LIGOURI, L. As novas tecnologias da informação e comunicação no campo dos velhos problemas e desafios educacionais. In: LITWIN, E. (Org). Tecnologia Educacional: política, histórias e propostas. Porto Alegre: Artes Médicas, p. 23-49, 1997.

LÜDKE, M. e ANDRÉ, M. Pesquisa em educação: abordagens qualitativas. São Paulo: EPU, 1986. 
MENEZES, C. M. A. Educação continuada de educadores: superando ambiguidades conceituais. In: Revista da FAEEBA - Educação e Contemporaneidade. Salvador-BA, v.12, n. 20, p. 311-320, jul/dez, 2003.

MOITA LOPES, L. P.; BASTOS, L. C. (Orgs). Para além da identidade: fluxos, movimentos e trânsitos. Belo Horizonte: Editora UFMG, 2010.

MOITA LOPES, L. P. Oficina de linguística aplicada: a natureza social e educacional dos processos de ensino/aprendizagem de línguas. Campinas: Mercado de Letras, 1996.

OLIVEIRA, R.S. Por uma prática reflexiva no ensino de línguas estrangeiras: saberes e diálogos. 367f. Tese (Doutorado em Letras - Estudos Linguísticos, Literários e Tradutológicos em Francês). Universidade de São Paulo-USP, São Paulo-SP, 2010. PERRENOUD, P. A prática reflexiva no oficio do professor: profissionalização e razão pedagógica. Tradução de Cláudia Schilling. São Paulo/SP: Editora Artmed, 2002. PRABHU, N. There is no best method - Why? In: Tesol Quarterly, Michigan, v. 24, n. 2, Summer, p. 161-176,1990.

RAMOS, R.C.G. Um olhar avaliativo para o módulo Fundamentos para a Avaliação e Preparação de Material Didático. In: CELANI, M.A.A (Org.) Reflexōes e Ações (Trans)formadoras no Ensino-aprendizagem de Inglês. Campinas: Mercado de Letras, p. 57-72, 2010.

RIZZINI, I. Pesquisando... Rio de Janeiro: Editora Universitária Santa Úrsula, 1999. SMOLKA, A. L. B. Sobre significação e sentido: uma contribuição à proposta de rede de significaçôes. In: ROSSETTI-FERREIRA, M. C. et al. (Orgs.). Rede de significaçôes e o estudo do desenvolvimento humano. Porto Alegre: Artes Médicas, p. 77-83, 2004.

SZUNDI, P.T.C. Construção do conhecimento sobre a futura prática pedagógica: reflexões de alunos-professores sobre um projeto de prática de ensino de língua inglesa. In: TELLES, J. A. (Org.). Formação Inicial e continuada de professores de linguas: dimensões e ações na pesquisa e na prática. Campinas: Pontes, p. 167-182, 2009.

TARDIF, M.; LESSARD, C. O Trabalho Docente: elementos para uma teoria da docência como profissão de interações humanas. Tradução de João Batista Kreuch. $3^{a}$ ed. Petrópolis: Vozes, 2005.

TARDIF, M. Saberes docentes e formação profissional. Tradução de Francisco Pereira. 9a ed. Petrópolis: Vozes, 2002.

UOL EDUCAÇÃO. Mais de 380 mil docentes da educação básica estão em cursos de graduação. NE10-UOL. 2011. Disponível em: <http://ne10.uol.com.br/canal/ educacao/noticia/2011/03/10/mais-de-380-mil-docentes-da-educacao-basicaestao-em-cursos-de-graduacao-260512.php> .Acesso em: 5 nov. 2013. 
VIAN JR, O. A educação linguística do professor de inglês. In: SZUNDI, P. T. C. et al. Linguistica Aplicada e Sociedade: ensino e aprendizagem de línguas no contexto brasileiro. Campinas: Pontes, p. 61-76, 2011.

VIEIRA-ABRAHÃO, M.H. A formação de professores de línguas: presente, passado e futuro. In: SILVA, K.A. (Org.) Ensinar e Aprender Linguas na Contemporaneidade: linhas e entrelinhas. Campinas: Pontes, p. 225-234, 2010.

VYGOTSKY, L. A construção do pensamento e da linguagem. Tradução de Paulo Bezerra. 2a ed. São Paulo-SP: Martins Fontes, 1934/2010.

YÁZIGI INTERNEXUS. Centro de Linguística Aplicada. Teacher Education Preservice Programm Booklet. São Paulo-SP, 2005.

Data de submissão: 04/07/2014. Data de aprovação: 23/02/2015. 